\title{
Phase 1 evaluation of tubing PEP as an improvised positive expiratory pressure device: pressures generated through oxygen tubing across a range of flow rates and lengths
}

Ianthe J. Boden ${ }^{1 *}$ and Julie C. Reeve ${ }^{2}$

*Correspondence: ianthe.boden@ths.tas.gov.au

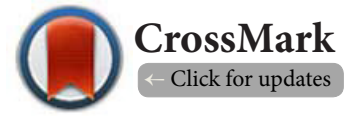

'Department of Physiotherapy, Launceston General Hospital, Launceston, Tasmania, Australia.

${ }^{2}$ School of Clinical Sciences, Faculty of Health and Environmental Sciences, Auckland University of Technology, Auckland, New Zealand.

\begin{abstract}
Introduction: Positive expiratory pressure (PEP) devices are widely used for respiratory therapy. Cost and accessibility of commercial devices can be preclusive, leading to therapists using improvised PEP devices. There are very few studies describing a new improvised PEP device: Tubing PEP. The purpose of this study was to compare pressures generated by different lengths of $4 \mathrm{~mm}$ internal diameter hospital-issue oxygen tubing and to estimate if therapeutic PEP could be delivered with tubing PEP.

Methods: $4 \mathrm{~mm}$ internal diameter oxygen tubing was cut into lengths of $40,60,80,100$, and $120 \mathrm{~cm}$ The pressure generated through each length was tested at gas flows of 4 to $11 \mathrm{~L} / \mathrm{min}$ in $1 \mathrm{~L} / \mathrm{min}$ increments. Pressure manometer measurements were taken visually three times for each flow rate and the mean of these measures calculated and recorded.
\end{abstract}

Results: There was a strong positive linear relationship between pressure and flow across lengths of oxygen tubing up to $120 \mathrm{~cm}$ with flow rates from 4 to $11 \mathrm{~L} / \mathrm{min}$. Regression modelling can estimate pressures generated with physiological flow rates to $20 \mathrm{~L} / \mathrm{min}$.

Conclusions: Tubing PEP consisting of $4 \mathrm{~mm}$ internal diameter oxygen tubing behaves as a flow-regulated $\mathrm{PEP}$ device. It is estimated that $\geq 60 \mathrm{~cm}$ lengths of tubing could provide therapeutic $\mathrm{PEP}$ of $10-20 \mathrm{~cm} \mathrm{H}_{2} \mathrm{O}$ throughout the expected range of physiological flow rates in subjects with respiratory pathology. This requires further confirmatory in-vivo testing. Tubing PEP is a viable, low-cost, readily available, low-risk, waterless, flow-regulated means of administering PEP.

Keywords: PEP, positive expiratory pressure, tubing, physiotherapy, respiratory therapy, expiratory flow

\section{Introduction}

Positive expiratory pressure (PEP) therapy generates an increase in transluminal airway pressure by creating resistance to air flow during expiration. This increase in airway pressure prevents airway collapse, increases lung volumes, assists with secretion clearance, and improves alveolar ventilation [1]. Two independent physical principles underpin a PEPs device's method of generating pressure during expiration: flow-regulation or pressure-regulation. Flow-regulated devices function by exhalation through a mouthpiece or mask with a small aperture outlet whereby pressure is generated according to the Hagen-Poiseuille Law $\left(\mathrm{P}=\mathrm{Q} 8 \mathrm{hL} / \mathrm{pr}^{4}\right)$.
Pressure $(P)$ is inversely related to the aperture diameter $(r)$ and directly dependent on driving flow rate $(\mathrm{Q})$; a smaller aperture or higher flow rate produces higher pressure. As expiration flow rate diminishes, airway pressure reduces. In contrast, with pressure-regulated devices, airway pressure remains constant throughout expiration and is independent of flow rate [3]. Pressure is generated via expiration against a spring loaded valve or column of water. Once a threshold pressure is achieved against the spring's tension or height of water, expiration starts. Regardless of the method, therapeutic levels of low-PEP are considered to be around $10-20 \mathrm{~cm} \mathrm{H}_{2} \mathrm{O}$ [1]. This is distinct from high-PEP with target PEP up to $120 \mathrm{~cm} \mathrm{H}_{2} \mathrm{O}$ [4]. 
PEP devices are used across many patient populations [5-9] and countries [10-14]. Commercially manufactured PEP devices such as TheraPEP ${ }^{\circledR}$ (DHD Smiths Medical), PEP/RMT ${ }^{\circledR}$ (Medimex $\mathrm{GmbH}$ ), Flutter VRP $1^{\circledR}$ (Aptalis Pharma US), Acapella ${ }^{\circledR}$ (Smiths Medical), Aerobika ${ }^{\circledR}$ (Trudell Medical) have been clearly described with clinical applications and efficacy documented [1]. In addition to commercial devices, some clinicians have constructed improvised devices such as bubble PEP [5] and recently, this has led to a developing market in commercial bubble PEP devices such as Therabubble ${ }^{\circledR}$ (Physiotherapy Innovations) and Hydrapep ${ }^{\circledR}$ (Resolve Healthcare).

Bubble PEP was introduced in the 1970's [15] and surveys report that most hospital-based therapists choose this device over others $[\mathbf{1 0}, \mathbf{1 1}, \mathbf{1 6}]$ because of cost and accessibility [11]. At its simplest, it comprises of a container that is partially filled with water and a tube, whose distal tip is submerged into the water, into which the patient exhales. However there are safety concerns regarding potential water-borne bacterial contamination, inadvertent aspiration of water [17] and, in the case of non-commercial bubble PEP devices, the inconsistency of assembly of bubble PEP $[11,18]$. To obtain a valid pressure-regulated system, bubble PEP tubing must be at least $20 \mathrm{~cm}$ long and have an inner diameter and apparatus air-escape aperture of $\geq 8 \mathrm{~mm}$ [18]. However, surveys report a variety of tubing diameters, lengths, volume of container and apertures used in the administration of bubble PEP $[11,16]$. Non-standardised clinician manufactured bubble PEP risks providing suboptimal or, at worst, excessive levels of pressure which could increase work of breathing leading to respiratory muscle fatigue [18]. Additionally, some patients may not tolerate bubble PEP as it is a pressure-regulated PEP device. Hypothetically, due to the difference between pressureregulated and flow-regulated devices and the timing of flow initiation on expiration, it is reported that some patients may better tolerate a flow-regulated device [3].

Given the cost of commercial PEP devices, the degree of assembly error with clinician manufactured improvised devices, possible hygiene risks, and patient usage limitations with bubble PEP [11], an alternative device that ameliorates these risks would be a useful addition to the battery of therapeutic PEP devices. Ideally this device should be flow-regulated, low-cost, readily available, and water-less. Tubing PEP was first proposed by Boden in 2009 [19] to meet these requirements and its implementation in some hospitals in Australia has since been reported [16].

Tubing PEP may act as a flow-regulated PEP device according to Hagen-Poiseuille's law, where airway pressure can be increased by expiration through long lengths of thin tubing. Hospital-issue $4 \mathrm{~mm}$ internal diameter oxygen tubing is a readily available piece of equipment fitting this description.

It is currently untested whether $4 \mathrm{~mm}$ oxygen tubing lengths could perform like a flow-regulated PEP device. Therefore, the aim of this study was to perform a phase 1, proof-of-concept, experimental study measuring pressures generated with flows of 4 to $11 \mathrm{~L} / \mathrm{min}$ in oxygen tubing of 4-mm internal diameter and in tubing lengths of 40,60,80, 100 and $120 \mathrm{~cm}$. Additionally, if tubing PEP behaves as a flow-regulated PEP device, to derive a formula that will estimate the lengths of tubing required to provide therapeutic PEP for patient use.

\section{Methods}

\section{Experimental setup}

This was an experimental study performed at the Physiotherapy Department at the Launceston General Hospital, Australia, with standardised benchtop apparatus (Figure 1). A flowmeter (Comweld Medical, Australia, range 0-15 L/min accuracy $+/-5 \%$ ) was connected to the hospital's external medical gas oxygen system to generate a constant flow from $4 \mathrm{~L} / \mathrm{min}$ to 11 $\mathrm{L} / \mathrm{min}$. These flow rates were chosen to provide an adequate series of data points to determine with confidence the relationship between flow, tubing length, and pressure within the flow limit restrictions of our experimental apparatus. A

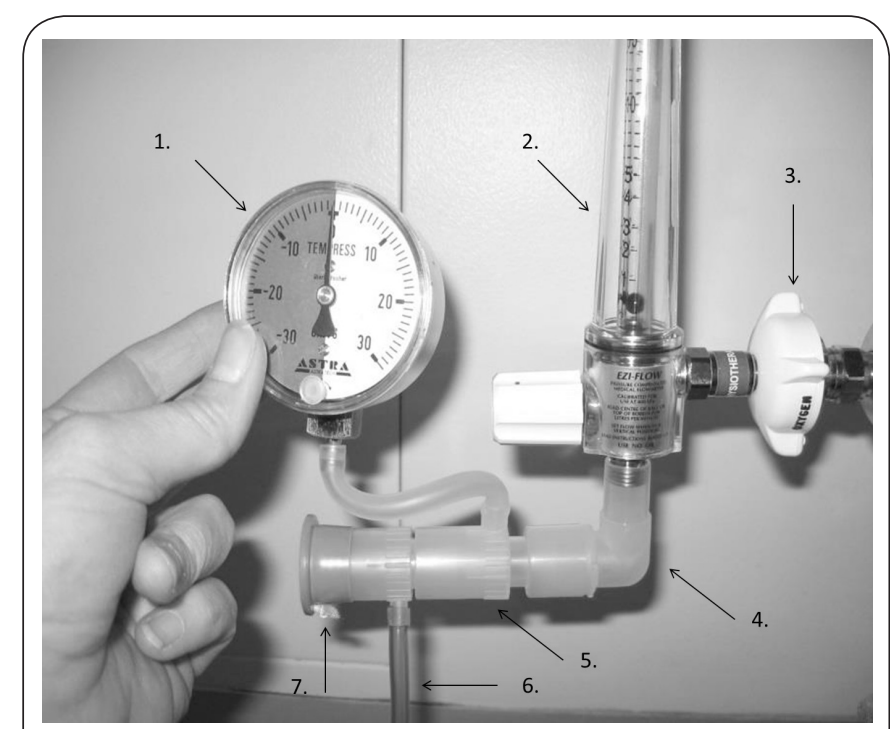

Figure 1. Experimental setup.

1. Pressure manometer, 2. Flowmeter, 3. External gas supply, 4. Elbow connector, 5. T-piece connector for manometer,

6. Oxygen tubing, 7. Capped T-piece connector for oxygen tubing.

T-piece was capped and connected to the flowmeter via an elbow connector. Oxygen tubing (a.p.s. Medical, Malaysia) with $4 \mathrm{~mm}$ internal diameter was attached to the T-piece $4 \mathrm{~mm}$ outlet. A manometer (AstraTech, Mölndal, Sweden, range $-30 \mathrm{~cm} \mathrm{H}_{2} \mathrm{O}-+30 \mathrm{~cm} \mathrm{H}_{2} \mathrm{O}$, increments of $1 \mathrm{~cm} \mathrm{H}_{2} \mathrm{O}$ ) was attached in series between the flowmeter and oxygen tubing via a second T-piece. A bio-technician calibrated the flowmeter and manometer immediately prior to measures being taken. This was done digitally at five increasing test points and five downscale test points to establish linearity and check hysteresis. All measures were taken over a single 
one-hour period. All connections in the system were checked between measures to ensure against air leaks.

A baseline measure of pressures generated with increasing flow rates through the $4 \mathrm{~mm}$ T-piece outlet (without additional oxygen tubing attached) was taken. Oxygen tubing was cut to $40 \mathrm{~cm}, 60 \mathrm{~cm}, 80 \mathrm{~cm}, 100 \mathrm{~cm}$, and $120 \mathrm{~cm}$ lengths. Sequentially each length was attached to the T-piece outlet and tested at $1 \mathrm{~L} / \mathrm{min}$ flow increments from $4 \mathrm{~L} / \mathrm{min}$ to $11 \mathrm{~L} / \mathrm{min}$. Flow delivery was determined by following manufacturer instructions for the height of the float ball in line with the flow delivery incremental markings. Pressure was measured visually from the manometer once flow rate stabilised and pressure was constant. Measures were repeated three consecutive times and the mean of these measures calculated and recorded.

\section{Statistics}

SPSS 15.0 (SPSS, Chicago, Illinois) was used for statistical analyses. The association between pressure, flow rate, and length of tubing was estimated using linear (ordinary least squares) univariate and multivariate regression analysis. Regression coefficients (with $95 \% \mathrm{Cl}$ and significance set at $\mathrm{p}<0.05$ ) were calculated to derive formulae for estimates of tube lengths and flow rates to be used to achieve desired airway pressures.

\section{Results}

Pressures obtained from different lengths of oxygen tubing with increasing flow rates are presented in Figure 2. Pressure increased linearly with increasing flow rates and increasing lengths of oxygen tubing. We observed very strong correlation $\left(R^{2}>95, p<0.001\right)$ between pressure and flow for all lengths of tubing within the measured flow rates. This enabled the development of a multi-regression model to determine pressures generated with variable tubing length and flow rates.

Pressure $=-8.15^{\mathrm{a}}+\left(\mathrm{Q} \times 1.33^{\mathrm{b}}\right)+\left(\mathrm{Lx} 0.082^{\mathrm{c}}\right)$

Pressure is measured in $\mathrm{cmH}_{2} \mathrm{O}$, constant (a) $95 \%$ confidence intervals (Cl) -9.81 to $-6.48, \mathrm{p}<0.001$; flow $(Q)$ in $\mathrm{L} / \mathrm{min}\left({ }^{\mathrm{b}}\right) 95 \%$ $\mathrm{Cl} 1.14$ to 1.52 , $\mathrm{p}<0.001$; tube length $(L)$ in $\mathrm{cm}\left({ }^{(}\right) 0.070$ to 0.092 , $p<0.001$. Estimates of pressure in each length of tubing to a flow rate of $20 \mathrm{~L} / \mathrm{min}$ are plotted in Figure 3.

\section{Discussion}

This is the first laboratory-based phase 1 study to examine tubing PEP's physical properties and to generate an equation to determine appropriate lengths of tubing required to generate therapeutic PEP. Our results demonstrate a strong linear relationship between pressure and flow with gas flow rates between 4-11 L/min through standard-issue oxygen tubing with an internal diameter of $4 \mathrm{~mm}$ and length up to $120 \mathrm{~cm}$. These findings are in agreement with the Hagen-Poiseuille law for laminar gas flow: when aperture diameter is kept constant, as the length of tube increases, pressure increases. These physical properties of flow and pressure with tubing PEP are similar to other flow-regulated PEP devices [20].

Our findings replicate the results of Mestriner et al., [18] who demonstrated that when a long tube $<7 \mathrm{~mm}$ diameter is used to construct bubble PEP, it leads to pressure becoming dependent on tubing length and flow rate, rather than the intended pressure-regulated device. Unfortunately, their findings were not able to confirm the hypothesis that lengths of tubing could independently be utilised for therapeutic PEP as baseline pressure was set at $10 \mathrm{~cm} \mathrm{H}_{2} \mathrm{O}$ accounting for the water column and the maximum length of tubing tested was 80

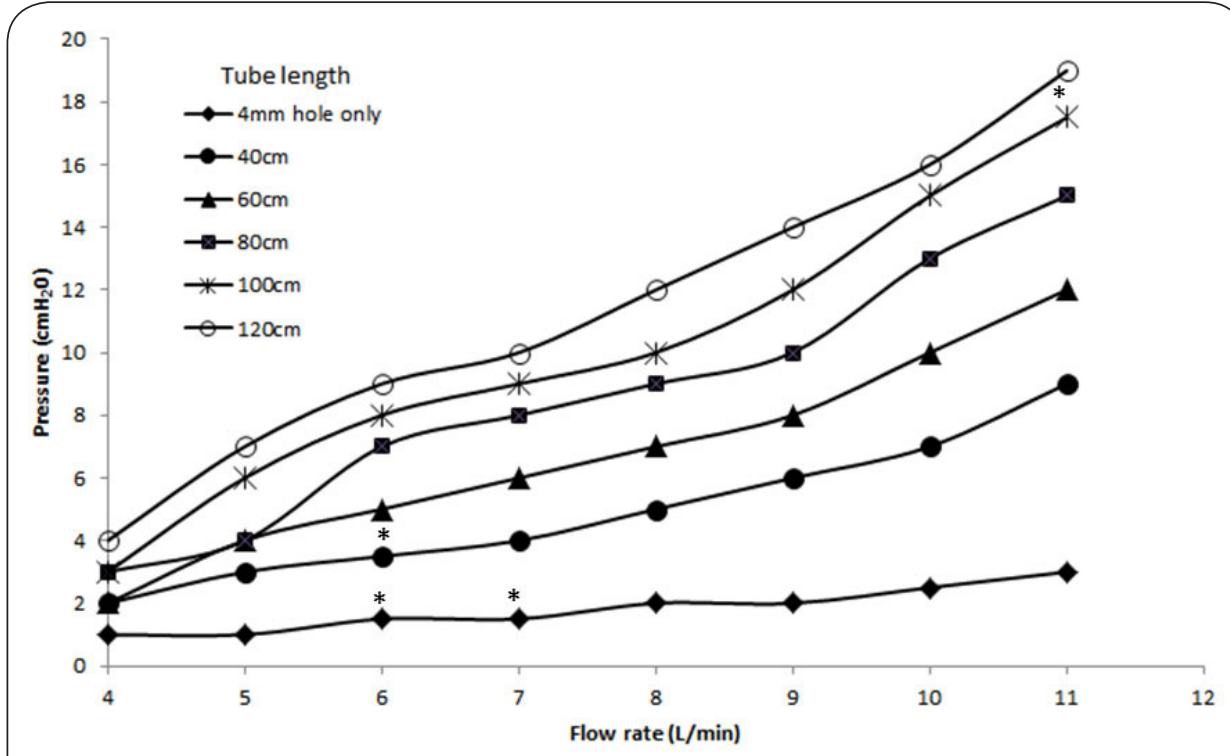

Figure 2. Flow versus pressure in 4-mm inner diameter oxygen tubing of varying lengths. $\mathrm{cm} \mathrm{H}_{2} 0$, centimetres of water pressure; $\mathrm{L} / \mathrm{min}$, litres per minute; $\mathrm{mm}$, millimetres, $\mathrm{cm}$, centimetres. ${ }^{*}$ Standard deviation (SD) was 0.3 . For all other measurements SD was zero. 


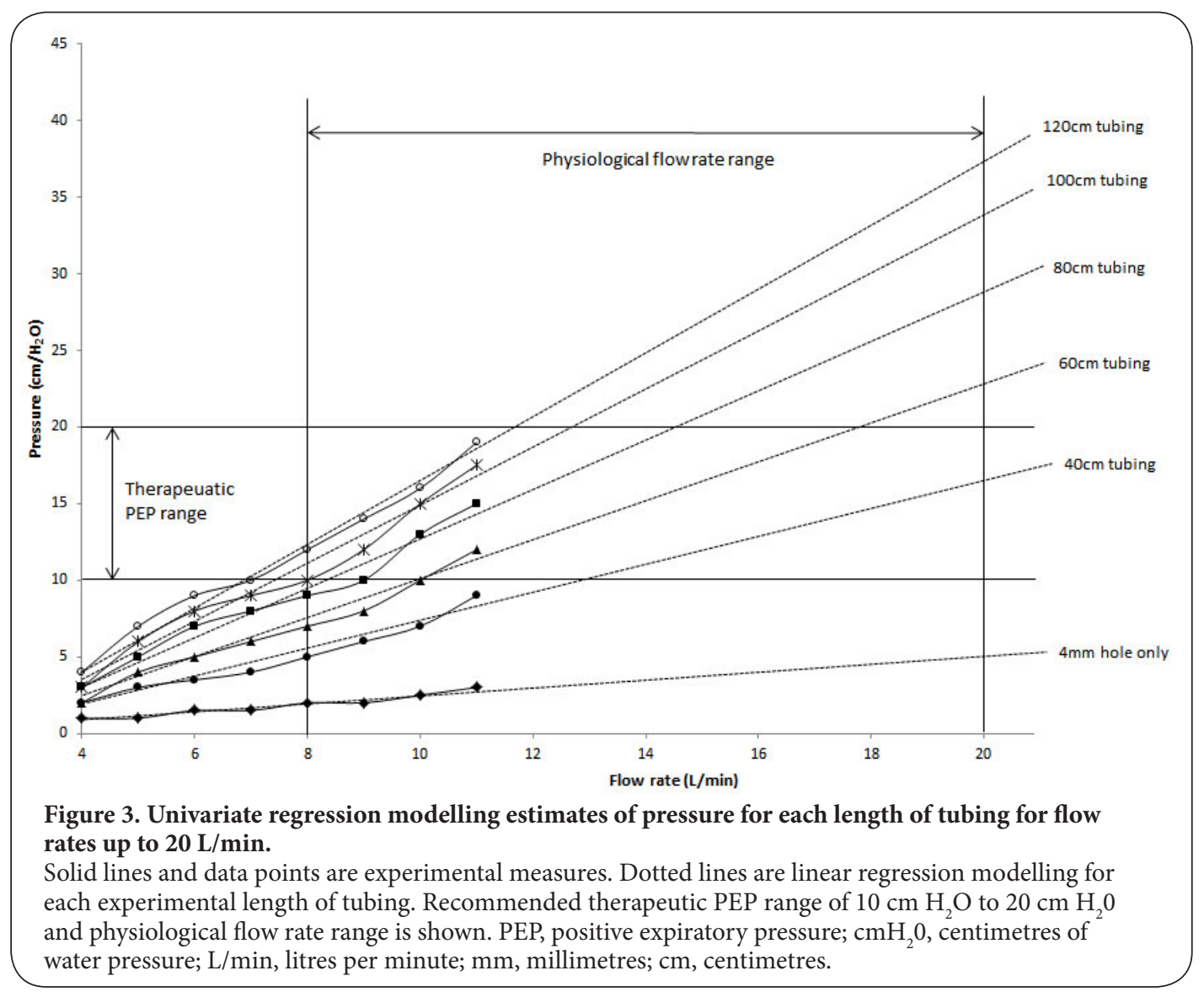

$\mathrm{cm}$. A post hoc manual data analysis where $10 \mathrm{~cm} \mathrm{H}_{2} 0$ was subtracted from each data point shows a strong agreement with our own data for similar lengths of $4 \mathrm{~mm}$ inner-diameter tubing.

Due to the strong linear relationship between pressure and flow for each given length of tubing, multi-regression modelling can estimate lengths of $4 \mathrm{~mm}$ diameter tubing required to achieve therapeutic levels of PEP $(10-20 \mathrm{~cm}$ $\mathrm{H}_{2} \mathrm{O}$ ) dependent upon the estimated patient expired flow rate. The PEP generated by a patient using tubing PEP, as for any other flow-regulated device, is dependent on the physiological expired flow rate of the individual patient. Flow rates measured during PEP therapy for normal healthy adults are $15-20 \mathrm{~L} / \mathrm{min}[\mathbf{3}, 21]$, whilst subjects with stable chronic obstructive pulmonary disease (COPD) are approximately $10 \mathrm{~L} / \mathrm{min}$ [22], and those with a cervical spinal cord injury are around $12 \mathrm{~L} / \mathrm{min}$ [21]. Our multi-regression modelling indicates that for an individual with normal expiratory flow rates a $40-60 \mathrm{~cm}$ tubing PEP length would provide $10-20 \mathrm{~cm}$ $\mathrm{H}_{2} \mathrm{O}$ pressure throughout expiration. In a patient with slower expiratory flow rates (e.g; COPD), a longer length of tubing PEP is required. Delivering therapeutic PEP with tubing PEP requires titration of the tubing length to achieve the desired pressures as measured with a manometer, and according to an individual's expiratory flow rate. If tubing PEP is adopted as a viable improvised PEP device, it has a number of advantages over existing improvised clinician-manufactured bubble PEP. Bubble PEP is one of the most common types of PEP device used in Australian $[11,16]$ and Swedish [12] hospitals due to cost and accessibility $[11,12]$. However, safety concerns regarding possible bacterial contamination [17], errors in assembly $[11,18]$, and cost of commercially available bubble PEP devices may be a limitation to usage. Tubing PEP is water less and can be constructed from a single piece of standardised hospital equipment thus limiting these concerns.

Bubble PEP has also been reported to have some patient dependent limitations. Sehlin et al., [3] reported that bubble PEP was less tolerated in intensive care patients compared to a flow-regulated PEP device. In-vivo use of bubble PEP with healthy subjects demonstrated different flow-rate timings and pressure-time functions compared to a flow-regulated PEP device. There is an immediate start to expiratory flow at the beginning of expiration when using a flow-regulated device, whereas with bubble PEP, flow does not start until a threshold pressure is met. It was hypothesised that in patients with respiratory pathology, this delay to expiratory flow could cause intolerance to Bubble PEP. As tubing PEP is a flow-regulated device and flow starts immediately upon expiration, it may be better tolerated.

Additionally, where it is difficult for physically weak patients to hold a bubble PEP device this should not be a problem 
with a single light piece of $40-80 \mathrm{~cm}$ tubing. With tubing PEP there are no water spillage issues, no gravity dependent positioning requirements, no moving parts, no breakable mechanical components, and it is quiet. Possible hygiene concerns from remnant condensation following use need establishing, however, the disposable nature of tubing PEP could make this concern redundant. Despite the physical properties and utility of tubing PEP having not yet been described, tubing PEP comprises $10 \%$ of hospital PEP devices in one region in Australia [16].

There is a risk that early adoption of tubing PEP prior to published materials and physiological testing of the device could lead to suboptimal PEP being prescribed. Expired flow rates vary amongst patients and within pathology groups. PEP generated in flow-dependent PEP devices, including tubing PEP, is dependent on these expired flow rates. To ensure that therapeutic PEP is delivered, longer tube lengths are required for patients with slower expiratory flow rates. Tubing PEP pressures in short lengths of oxygen tubing from 5 to 20 $\mathrm{cm}$ have been tested in hospital admitted adults with acute exacerbation of COPD and compared to pressures generated by healthy subjects [23]. Suboptimal pressures of less than $10 \mathrm{~cm} \mathrm{H}_{2} \mathrm{O}$ were generated in these short lengths of tubing. Indeed, our study confirms that tubing lengths of less than $20 \mathrm{~cm}$ would not provide therapeutic PEP for patients with COPD; rather $>60 \mathrm{~cm}$ length tube should be used. To confirm tubing PEP as a viable therapeutic PEP device, phase II experiments of tubing PEP in healthy subjects and patients with respiratory pathology of the appropriate length tubing $(40-80 \mathrm{~cm})$ is now required to measure for repeatability, safety, utility and practicality of administration.

The main limitation of our study is that flow rates beyond 11 $\mathrm{L} / \mathrm{min}$ were not tested. This was for two reasons. Firstly, physiological flow rates in patient populations for which tubing PEP is primarily intended for use are 8-12 L/min [22] and, secondly, measurement limitation of our experimental flow-meter. It is possible that flow rates more than $11 \mathrm{~L} / \mathrm{min}$ become turbulent and the Hagen-Poiseuille law for laminar gas flow no longer applies. As defined by Reynold's number [24], with faster flow rates the inertia of the gas interacts more significantly with the lining of the tube and resistance to flow increases. The relationship between pressure and flow changes from being linear to exponential. Our described linear relationship between pressure and flow would no longer be valid at higher flow rates and our regression formula and estimates would be false. However, it is reported that a linear relationship is maintained up to $20 \mathrm{~L} / \mathrm{min}[\mathbf{1 8 , 2 5}]$ in commercially available and improvised PEP devices. Expiratory flow rates measured during low-PEP in clinical and healthy populations range up to $20 \mathrm{~L} / \mathrm{min}$. Thus, our findings and model are relevant for use in patients with respiratory pathology and/or normal physiological range of flows.

Other limitations are the quality of the experimental apparatus and non-blinding of the measurement. Parallax error of setting the flow rate based on the float ball height in line with a marking on the flow meter could have introduced measurement error. More sophisticated electronic flow and pressure transducers with known standard error of measurement could have been used to improve the methodological quality of this experiment, the use of which was not fiscally viable for this clinician-initiated experimental study. The measurement of pressures was also taken by an assessor who was aware of the length of the tubing and the quality of this study could have been improved using a blinded assessor.

A further limitation is that only one variety of hospital supplied oxygen tubing was tested. There is a possibility that a different brand of $4 \mathrm{~mm}$ diameter oxygen tubing may have different material properties affecting the resistance to airflow through the tube. Olsen et al., [26] found that pressures generated by different resisters used in flow-regulated PEP devices were significantly different despite the stated aperture sizes being identical. Considering this, further testing of different varieties of oxygen tubing of similar diameters may be warranted.

Nonetheless, this is the first study to demonstrate that tubing PEP performs as a flow-regulated PEP device with pressures reaching levels that could deliver therapeutic levels of PEP.

\section{Conclusions}

This experimental study demonstrates that tubing PEP constructed from $4 \mathrm{~mm}$ internal diameter oxygen tubing performs as a flow-regulated PEP device. Modelling estimates that 40$80 \mathrm{~cm}$ lengths would provide therapeutic levels of low-PEP throughout a range of physiological flow rates. Further testing is required in-vivo with healthy subjects and those with respiratory pathology to assess tubing PEPs administration, safety, efficacy, and utility.

\section{Competing interests}

The authors declare that they have no competing interests.

\section{Authors' contributions}

\begin{tabular}{|l|c|c|}
\hline Authors' contributions & IJB & JCR \\
\hline Research concept and design & $\checkmark$ & -- \\
\hline Collection and/or assembly of data & $\checkmark$ & -- \\
\hline Data analysis and interpretation & $\checkmark$ & -- \\
\hline Writing the article & $\checkmark$ & $\checkmark$ \\
\hline Critical revision of the article & $\checkmark$ & $\checkmark$ \\
\hline Final approval of article & $\checkmark$ & $\checkmark$ \\
\hline Statistical analysis & $\checkmark$ & -- \\
\hline
\end{tabular}

\section{Acknowledgement}

The authors would like to thank Nadia Zalucki and Rebecca Cannell, Launceston General Hospital, Launceston, Tasmania, for reviewing the manuscript, Liz Konetschnik for copy editing the manuscript, and lain Robertson, Phd, Biostatisician, University of Tasmania, for assisting in the statistical analysis of the data.

\section{Publication history}

EIC: Victor J. Thannickal, University of Alabama at Birmingham, USA. Received: 31-Jan-2017 Final Revised: 24-Apr-2017

Accepted: 18-May-2017 Published: 27-May-2017 
Boden et al. Pulmonology and Respiratory Research 2017,

\section{References}

1. Fagevik Olsen $M$, Lannefors $L$ and Westerdahl E. Positive expiratory pressure - Common clinical applications and physiological effects. Respir Med. 2015; 109:297-307. | Article | PubMed

2. Darbee JC, Ohtake PJ, Grant BJ and Cerny FJ. Physiologic evidence for the efficacy of positive expiratory pressure as an airway clearance technique in patients with cystic fibrosis. Phys Ther. 2004; 84:524-37. | Article | PubMed

3. Sehlin M, Ohberg F, Johansson $G$ and Winso O. Physiological responses to positive expiratory pressure breathing: a comparison of the PEP bottle and the PEP mask. Respir Care. 2007; 52:1000-5. | Article | PubMed

4. Pfleger A, Theissl B, Oberwaldner B and Zach MS. Self-administered chest physiotherapy in cystic fibrosis: a comparative study of highpressure PEP and autogenic drainage. Lung. 1992; 170:323-30. | Article I PubMed

5. Bjorkqvist M, Wiberg B, Bodin L, Barany M and Holmberg H. Bottleblowing in hospital-treated patients with community-acquired pneumonia. Scand J Infect Dis. 1997; 29:77-82. | Article | PubMed

6. Elkins MR, Jones $A$ and van der Schans $C$. Positive expiratory pressure physiotherapy for airway clearance in people with cystic fibrosis. Cochrane Database Syst Rev. 2006; CD003147. | Article | PubMed

7. Orman J and Westerdahl E. Chest physiotherapy with positive expiratory pressure breathing after abdominal and thoracic surgery: a systematic review. Acta Anaesthesiol Scand. 2010; 54:261-7. | Article | PubMed

8. Lee AL, Williamson HC, Lorensini S and Spencer LM. The effects of oscillating positive expiratory pressure therapy in adults with stable non-cystic fibrosis bronchiectasis: A systematic review. Chron Respir Dis. 2015; 12:36-46. I Article | PubMed

9. Osadnik CR, McDonald CF, Jones AP and Holland AE. Airway clearance techniques for chronic obstructive pulmonary disease. Cochrane Database Syst Rev. 2012; CD008328. | Article | PubMed

10. Fiore JF, Chiavegato LD, Paisani DM and Colucci DB. Utilization of positive-pressure devices for breathing exercises in the hospital setting: a regional survey in Sao Paulo, Brazil. Respir Care. 2010; 55:719-24. | Article | PubMed

11. Santos MD, Milross MA and Alison JA. Therapist-made bubble-positive expiratory pressure: a survey of physiotherapists in Australia. Cardiopulmonary Physical Therapy Journal. 2016; 27:3-10. | Article

12. Johansson $H$, Sjöholm R, Stafberg A and Westerdahl E. Breathing Exercises with Positive Expiratory Pressure after Abdominal SurgeryThe Current Physical Therapy Practice in Sweden. J Anesthe Clinic Res. 2013; 4:2. | Article

13. Jones AY, Hutchinson RC and Oh TE. Chest physiotherapy practice in intensive care units in Australia, the UK and Hong Kong. Physiotherapy theory and practice. 1992; 8:39-47. | Article

14. Reeve J, Denehy L and Stiller K. The physiotherapy management of patients undergoing thoracic surgery: a survey of current practice in Australia and New Zealand. Physiother Res Int. 2007; 12:59-71. | Article I PubMed

15. Heisterberg L, Johansen TS, Larsen HW, Holm M and Andersen B. Postoperative pulmonary complications in upper abdominal surgery. A randomized clinical comparison between physiotherapy and blowbottles. Acta Chir Scand. 1979; 145:505-7. | Article | PubMed

16. Johnston $\mathrm{CL}$, James $\mathrm{R}$ and Mackney JH. The current use of positive expiratory pressure (PEP) therapy by public hospital physiotherapists in New South Wales. New Zealand Journal of Physiotherapy. 2013; 41:8893. | Pdf

17. Ferroni $A$, Werkhauser-Bertrand $A$, Le Bourgeois $M$, Beauvais $R$, Vrielynck S, Durand C, Lenoir G, Berche P and Sermet-Gaudelus I. Bacterial contamination in the environment of hospitalised children with cystic fibrosis. J Cyst Fibros. 2008; 7:477-82. | Article | PubMed

18. Mestriner RG, Fernandes RO, Steffen LC and Donadio MV. Optimum design parameters for a therapist-constructed positive-expiratorypressure therapy bottle device. Respir Care. 2009; 54:504-8. | Article | PubMed
19. Boden I. Tubing positive expiratory pressure: a simple, novel, cheap, and disposable method. Australian Journal of Physiotherapy. 2009; 55.

20. Christensen EF, Jensen RH, Schonemann NK and Petersen KD. Flowdependent properties of positive expiratory pressure devices. Monaldi Arch Chest Dis. 1995; 50:150-3. | Article I PubMed

21. Bodin $P$, Kreuter M, Bake B and Olsen MF. Breathing patterns during breathing exercises in persons with tetraplegia. Spinal Cord. 2003; 41:290-5. | Article | PubMed

22. van der Schans CP, de Jong W, de Vries G, Kaan WA, Postma DS, Koeter $\mathrm{GH}$ and van der Mark TW. Effects of positive expiratory pressure breathing during exercise in patients with COPD. Chest. 1994; 105:7829. | Article | PubMed

23. Robins D, Egan M, Johnston C, Newstead C and Mackney J. Pressures generated using an improvised PEP device in a COPD and healthy population. European Respiratory Journal. 2015; 46:PA982.

24. Chakrabarti S. A novel experimental setup to study the HagenPoiseuille and Bernoulli equations for a gas and determination of the viscosity of air. European Journal of Physics. 2015; 36:065046. | Article

25. Dagan Y, Wiser I, Weissman O, Farber N, Hundeshagen G, Winkler E, Kazula-Halabi T and Haik J. An Improvised "Blow Glove" Device Produces Similar PEP Values to a Commercial PEP Device: An Experimental Study. Physiother Can. 2014; 66:308-12. | Article | PubMed Abstract | PubMed FullText

26. Fagevik Olsen M, Carlsson M, Olsen E and Westerdahl E. Evaluation of Pressure Generated by Resistors From Different Positive Expiratory Pressure Devices. Respir Care. 2015; 60:1418-23. | Article | PubMed

\section{Citation:}

Boden IJ and Reeve JC. Phase 1 evaluation of tubing PEP as an improvised positive expiratory pressure device: pressures generated through oxygen tubing across a range of flow rates and lengths. Pulmonol Respir Res. 2017; 5:1. http://dx.doi.org/10.7243/2053-6739-5-1 